\title{
Original Article \\ Biofilm formation and detection of A/D genes in MRSA (Methicillin-Resistant Staphylococcus aureus) and MSSA (Methicillin-Sensitive Staphylococcus aureus)
}

\author{
Department of Biomedic, Medical Faculty, Wijaya Kusuma University, Surabaya, Indonesia
}

\begin{abstract}
MRSA (Methicillin-Resistant Staphylococcus aureus) arises due to excessive use of methicillin antibiotics and complications from all medical practices that have been carried out lately. The prevalence of MRSA tends to increase and its ability to form biofilms so that it has the potential to significantly increase mortality and morbidity. Biofilms are considered one of the microbial virulence factors. Biofilm formation in S. aureus is regulated by the expression of PIA which mediates attachment between cells to cells and is a product of the ABDC ica gene. This study aims to determine the ability of biofilm formation as one of the virulence factors in MRSA compared to MSSA (Methicillin-Sensitive Staphylococcus aureus) . its relationship to the presence of $\mathrm{A}$ and $\mathrm{D}$ ica genes as biofilm coding genes. Biofilm formation assay on MRSA and MSSA using the Microtiter Plate (MtP) method and the A/D gene detection assay performed by PCR method. The results showed that the incubation end value of Optical Density (OD) for MSSA1 (0.75), MSSA2 (0.46), MRSA1 (0.53) isolates according to the formula were interpreted as moderate biofilm producer. The conclusions of this study were all of the test isolates (MSSA1, MSSA2 and MRSA1) were able to form a biofilm. Distribution of $i c a$ A and ica D genes in MSSA 1 and MSSA 2 was varied while MRSA1 had the ica A and ica D genes.
\end{abstract}

Keywords: Biofilm, ica A/D gene, MRSA, MSSA

Received: 29 September 2018 Revised: 09 May 2019 Accepted: 15 June 2019

\section{Introduction}

Bacterial resistance to various antibiotics is a worldwide problem (pandemic) that is not less important than the problem of infection/virulence of the bacteria itself. One of the important bacterial resistances to be noticed is Methicillin-Resistant Staphylococcus aureus (MRSA) (Yuwono \& Biomed, 2010). MRSA is a type of $S$. aureus or also called Methicillin Sensitive Staphylococcus aureus (MSSA) that is resistant to methicillin antibiotics and other class medications, such as penicillin, amoxicillin, and oxacillin.

A survey conducted in 2008 in ten cities in Indonesia shows that the prevalence of MRSA is quite high, at $27 \%$, where Surabaya $(40 \%)$ keeps the third-largest after Makassar (100\%) and Jakarta (54\%), followed by Semarang (36\%), Yogyakarta (31\%), Bandung (23\%), Padang (21\%), Malang (19\%), Solo (17\%) and Denpasar (7\%) (The first multicenter study, 2008).

MRSA creates a large risk and has the potential to cause significant mortality and morbidity in the human population because it is able to form a biofilm. Biofilm has a considerable impact on health and are estimated to be associated with $65 \%$ of nosocomial infections (Kaur \& Wankhede, 2014). Riemann and Oliver (2006), defines the biofilm as a collection of microorganisms and associated extracellular products on its surface and

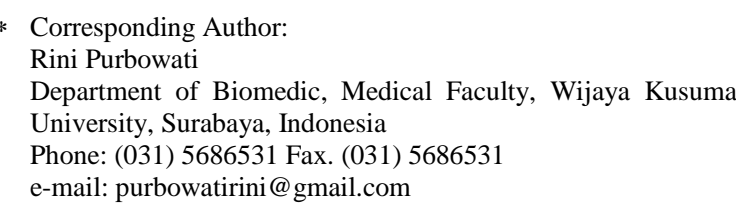

commonly attached to biological and non-biological substrates.

The formation of biofilm in S. aureus is governed by PIA expression mediating cell-to-cell attachment and is the product of the genes of ABDC ica (Kaur \& Wankhede, 2014). The product of the ica A gene is a homologous transmembrane protein with $\mathrm{N}$-acetylglucosaminyltransferase, which requires the ica $\mathrm{D}$ gene product for its optimum activity. The $\mathrm{N}$-acetylglucosamine Oligomer produced by ica $\mathrm{AD}$ reaches a maximum length of 20 residues and it occurs only when the ica $\mathrm{AD}$ is coexpressed with ica $\mathrm{C}$, which allegedly encodes a membrane protein, whose oligomeric chain is longer. (O'Gara, 2007).

Infection accompanied by biofilm formation becomes a major problem, as it is difficult to be managed effectively by the host immune system and is resistant to treatment with antimicrobials. Such protection mechanisms are thought to preclude the absorption and penetration of antibiotics through the biofilm matrix (Cavaliere et al., 2014). Biofilm is known to be involved in various kinds of microbial infections in the body. It is estimated that nearly $80 \%$ of all infections (Ghafourian et al., 2013).

Eftekhar and Dadaei (2010) in their study showed that $55 \%$ of MRSA isolates were able to form biofilm and $75 \%$ of MRSA isolates contained ica operon. Previous research by Nuryastuti (2013) showed that the presence of ica A / D genes in chromosomes in MRSA and MSSA isolates is not always followed by the ability of MRSA bacteria to form biofilms. Operon ica in S. epidermidis and $S$. aureus is influenced by environmental factors but its expression is more closely controlled in S. aureus. The ability of the biofilm-forming in vitro greatly depends on the type of strain of S. aureus (Eftekha \& Dadaei, 2010). 
This study aims to identify and analyze the ability of biofilm formation in MRSA and MSSA isolates, ica A/D genes distribution associated with biofilm formation, thus

\section{Methods}

\section{Bacterial Strain, Media and Growth Condition}

The test bacterial isolates used in this study are MSSA1, MSSA2, and MRSA1. Bacterial MSSA1 isolates collection was obtained from microbiology laboratory, Faculty of Medicine, Wijaya Kusuma Surabaya University, bacterial MSSA 2 and MRSA 1 isolates collection were obtained from microbiology laboratory, Faculty of Medicine, Airlangga Surabaya University. All of the isolates were subcultures from stocks onto NA (Nutrient Agar) medium and incubated at $37{ }^{\circ} \mathrm{C}$ overnight.

\section{Study of Biofilm Formation on MRSA and MSSA by Microtiter Plate Method (MtP)}

The microtiter plate method was conducted previously by Meritt et al. (2005) with modification. The overnight culture of MSSA1, MSSA2, and MRSA1 were inoculated in $5 \mathrm{~mL}$ of Luria Bertani broth supplemented with $2 \%$ sucrose and incubated overnight at $37{ }^{\circ} \mathrm{C}$. The overnight culture of the test isolates was diluted by fresh Luria Bertani broth supplemented with $2 \%$ sucrose medium to $\mathrm{OD}_{600}=1(1 \%)$ then used to inoculated 96-well flat bottom polystyrene microtiter plates containing $150 \mu \mathrm{L}$ fresh Luria Bertani broth supplemented with $2 \%$ sucrose. The plate was incubated in shaker $(80 \mathrm{rpm}$, orbitak shaker) at room temperature for $4 \mathrm{~h}$ and then the plate were incubated at $37^{\circ} \mathrm{C}$ for $\pm 48 \mathrm{~h}$. After incubation, the plates were carefully washed 4 times with sterile phosphate buffer saline (PBS) to remove planktonic bacteria and were air-dried in an inverted position before being stained. The plate was stained with $0.1 \%$ crystal violet solution of $100 \mu \mathrm{L}$ for $30 \mathrm{~min}$. The residual staining liquid is washed with sterile distilled water until no color in the rinse water, then allowed to air-dry. Finally $100 \mu \mathrm{L}$ DMSO $100 \%$ was added into each well before being read. Furthermore, the culture was analyzed by microtiter plate absorbance reader to analyze its absorbance at $590 \mathrm{~nm}$. Each isolate performed twelve replications. The interpretation of results is described as follows: (If ODs $\leq$ $\mathrm{ODc}=$ nonbiofilm producer; $\mathrm{ODc} \leq \mathrm{ODs} \leq 2 \times \mathrm{ODc}=$

\section{Results}

This research was conducted at the Laboratory of Gastroentrenteritis and Salmonellosis, Institute of Tropical Disease (ITD), Airlangga University, to find out the ability of biofilm formation of MRSA (MethicillinResistant Staphylococcus aureus) and MSSA (Methicillin-Sensitive Staphylococcus aureus) by microtiter plate (MtP) method and detection of ica A/D genes as encoding of biofilm formation in MRSA and MSSA isolates. providing preliminary data on biofilm formation capacity ratio in these two strains of bacteria.

weak biofilm producer; $2 \times$ ODc $\leq$ ODs $\leq 4 \times$ ODc $=$ moderate biofilm producer; $4 \times$ ODc $<$ ODs $=$ strong biofilm producer; (description: ODc $=$ OD negative control, ODs = OD sample)). Staphylococcus epidermidis was used as the biofilm producer control strain, based on a preliminary test that showed no biofilm was formed (Gowrishhanker et al., 2016).

\section{Detection of ica A/D Genes}

Extraction of bacterial DNA was performed by the boiling process. After overnight culture Nutrient Agar medium 3-5 colonies were suspended in TAE buffer $\mathrm{pH}=$ 2 , the suspension was boiled at $98{ }^{\circ} \mathrm{C}$ for $10 \mathrm{~min}$ in the water bath then centrifuged at $10.000 \mathrm{rpm}$ for $5 \mathrm{~min}$. An aliquot of the supernatant was used as a DNA template for PCR or store at $-20^{\circ} \mathrm{C}$ if not directly analyzed.

The selected primer is based on the base order available at the National Center for Biotechnology Information gene bank (locusAF086783) and Sequences of oligonucleotide primers for PCR amplification of biofilm-associated genes in MSSA1, MSSA2, and MRSA1 isolates are shown in the following Table 1.

The PCR assay for detection of ica A/D genes was performed using the primer (forward and reverse). Solution 1 (for 6 samples) with compositions: $75 \mu \mathrm{L}$ PCR Mix, $6 \mu \mathrm{L}$ forward primer, $6 \mu \mathrm{L}$ reverse primer, and $3 \mu \mathrm{L}$ $\mathrm{H}_{2} \mathrm{O}$. An aliquot of $5 \mu \mathrm{L}$ of DNA template was added to $15 \mu \mathrm{L}$ solution 1 so that the total volume in microtube is $20 \mu \mathrm{L}$. Amplification was performed by using Thermal Sickle with thermal cycling profile as follows: initial denaturation at $94{ }^{\circ} \mathrm{C}$ for 2 minutes, (denaturation at 95 ${ }^{\circ} \mathrm{C}$ for $1 \mathrm{~min}$, annealing at $56.9{ }^{\circ} \mathrm{C}$ for $1 \mathrm{~min}$ and extension at $72{ }^{\circ} \mathrm{C}$ during $1 \mathrm{~min}$ ) with 30 cycles and a final extension at $72{ }^{\circ} \mathrm{C}$ for $5 \mathrm{~min}$. (Eftekhar and Dadaei, 2011). Amplified PCR product was analyzed by $2 \%$ agarose gel, $1 \mathrm{X}$ TAE, 80 volts, 400 milliamperes for 20 min, stained with ethidium bromide $10 \mathrm{mg} / \mathrm{mL}$ and visualized under UV-illuminator. Staphylococcus aureus ATCC 25923 was used as a positive control strain or the model strain and sterile distilled water was used as a negative control (Yousefi et al., 2016).

The biofilm formation of MSSA1, MSSA2 and MRSA1 isolates by MtP method is shown in Figure 1. The bacterial cells were grown in 96-well flat-bottom polystyrene microtiter plates containing Luria Bertani Broth medium supplemented with $2 \%$ sucrose. The cells that adhered to the plate surface after washing with sterile PBS were visualized by crystals violet staining.

Determination of the ability of biofilm formation was conducted by quantitative analysis with MtP method that 
analyzing the value of OD (Optical Density) at the beginning and end of incubation with the microtiter plate reader. Result of biofilm formation for MSSA1, MSSA2, and MRSA1 isolates is presented in Table 2.

According to Table 2, the biofilm formation ability for MSSA1, MSSA2, and MRSA1 isolates showed that all of the selected isolates were found moderate biofilm producer. The OD value of the end of incubation for MSSA1, MSSA2 and MRSA1 isolates is greater than or equal to 2 times of the OD value of the end of incubation on control $(0.750)$ or greater than or equal to 1.501 . It is also less than or equal to 4 times of the OD value of the end of incubation on control or less than or equal to 3.001 according to the formula used, it is interpreted as moderate biofilm producer.

Detection of ica A/D genes as encoding gene of biofilm formation for MSSA1, MSSA2 and MRSA1 isolates was conducted by using the PCR technique. The primer used was obtained from PT. Genetika Science Indonesia, Manufacturer: Integrated DNA Technologies. Sequences of oligonucleotide primers for PCR amplification of biofilm-associated genes in MSSA1, MSSA2, and MRSA1isolates are shown in Table 1. Result of PCR amplification for detection of ica A gene (A) and ica D gene (B) responsible for biofilm formation on (1) MSSA1, (2) MSSA2 and (3) MRSA1 isolates is shown in Figure 2.

Table 3 shows that the presence of ica A/D genes on Staphylococcus $\mathrm{sp}$. bacteria shows varied results. MSSA1 isolate was found in ica A gene, but it was not found in ica D gene. While, the MSSA2 isolate was not found in ica A gene, but it was found in ica D gene, and MRSA1 isolate was found in both ica A and ica $\mathrm{D}$ genes.

Table 1. Sequences of oligonucleotide primers for PCR amplification of biofilm associated genes in MSSA 1, MSSA 2, and MRSA 1isolates.

\begin{tabular}{|c|c|c|c|c|c|}
\hline Gene & $\begin{array}{l}\text { Primer } \\
\text { name }\end{array}$ & Primer Sequence (5'-3') & Product size (bp) & PCR Program & M-PCR Volume \\
\hline ica & $\mathrm{A}$ & $\begin{array}{l}\mathrm{F}: \text { GTTGTCGACGTTGGCTACTG } \\
\mathrm{R}: C G A C A A G A A C T A C T G C T G C G\end{array}$ & $523 \mathrm{bp}$ & $\begin{array}{l}1 \text { cycle } \\
\left(94^{\circ} \mathrm{C}----2 \mathrm{mnt}\right)\left(94^{\circ} \mathrm{C}----1 \mathrm{mnt}\right) \\
\left(56,9^{\circ} \mathrm{C}--1 \mathrm{mnt}\right) \\
\left(72^{\circ} \mathrm{C}----1 \mathrm{mnt}\right) \\
\left(72^{\circ} \mathrm{C}----5 \mathrm{mnt}\right) \\
\left(4^{\circ} \mathrm{C}----\infty\right)\end{array}$ & $20 \mu \mathrm{L}$ \\
\hline ica & $\mathrm{D}$ & 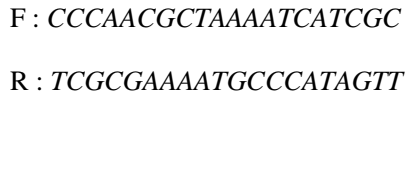 & $212 \mathrm{bp}$ & $\begin{array}{l}1 \text { cycle } \\
\left(94^{\circ} \mathrm{C}----2 \mathrm{mnt}\right)\left(94^{\circ} \mathrm{C}----1 \mathrm{mnt}\right) \\
\left(56,9^{\circ} \mathrm{C}--1 \mathrm{mnt}\right) \\
\left(72^{\circ} \mathrm{C}---1 \mathrm{mnt}\right) \\
\left(72^{\circ} \mathrm{C}----5 \mathrm{mnt}\right) \\
\left(4^{\circ} \mathrm{C}---\infty\right)\end{array}$ & $20 \mu \mathrm{L}$ \\
\hline
\end{tabular}

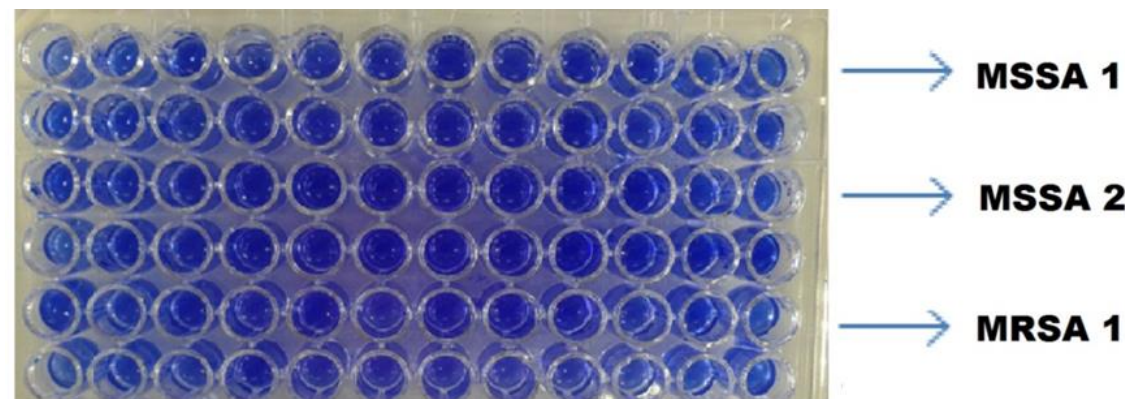

Figure 1. The biofilm formation of MSSA 1, MSSA 2 and MRSA 1 isolates by MtP method.

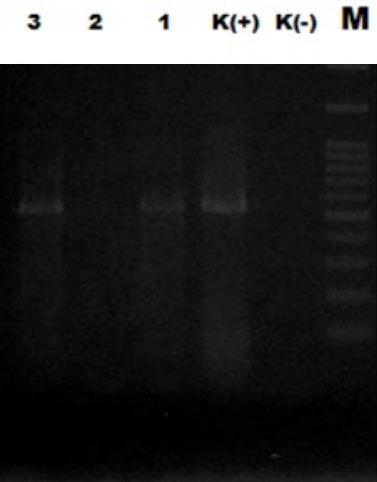

A

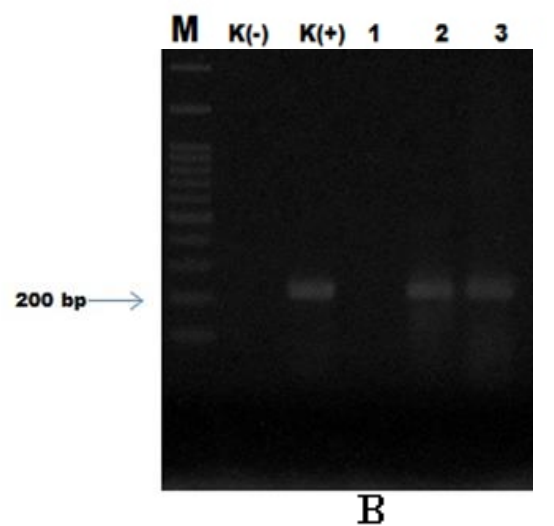

Figure 2. Result of PCR amplification for detection of genes ica A, $523 \mathrm{bp}$, (A) and ica D, 212 bp, (B) responsible for biofilm formation for (1) MSSA1, (2) MSSA2 and (3) MRSA1 isolates. 
Table 2. Result of biofilm formation (Optical Density) for MSSA1, MSSA2, and MRSA1

\begin{tabular}{|c|c|c|c|c|}
\hline \multirow{2}{*}{ Replication } & \multicolumn{4}{|c|}{ Strain ID } \\
\hline & Negative control & MSSA1 & MSSA2 & MRSA1 \\
\hline 1 & 0.902 & 1.015 & 2.615 & 2.223 \\
\hline 2 & 1.079 & 1.753 & 2.204 & 1.634 \\
\hline 3 & 1.416 & 2.960 & 2.324 & 1.628 \\
\hline 4 & 0.847 & 3.460 & 2.579 & 2.156 \\
\hline 5 & 0.918 & 1.367 & 3.369 & 2.591 \\
\hline 6 & 0.908 & 2.688 & 2.704 & 1.956 \\
\hline 7 & 0.244 & 3.174 & 3.149 & 2.653 \\
\hline 8 & 0.577 & 1.957 & 2.732 & 2.960 \\
\hline 9 & 0.464 & 2.575 & 2.427 & 2.533 \\
\hline 10 & 0.313 & 2.130 & 3.205 & 1.516 \\
\hline 11 & 0.388 & 1.825 & 1.693 & 3.100 \\
\hline 12 & 1.198 & 1.841 & 2.259 & 2.013 \\
\hline Average & 0.771 & 2.229 & 2.605 & 2.247 \\
\hline $\begin{array}{l}\text { Standard } \\
\text { Deviation }\end{array}$ & 0.356 & 0.746 & 0.476 & 0.526 \\
\hline Category & - & Moderate biofilm producer & $\begin{array}{l}\text { Moderate biofilm } \\
\text { producer }\end{array}$ & Moderate biofilm producer \\
\hline
\end{tabular}

Table 3. Presence of ica A/D genes on MSSA 1, MSSA 2, and MRSA 1 isolates

\begin{tabular}{lcc}
\hline \multirow{2}{*}{ Bacterial Isolate } & \multicolumn{2}{c}{ Result } \\
\cline { 2 - 3 } & ica A & ica D \\
\hline MSSA 1 & $(+)$ & $(-)$ \\
MSSA 2 & $(-)$ & $(+)$ \\
MRSA 1 & $(+)$ & $(+)$ \\
\hline
\end{tabular}

\section{Discussion}

Using excessive methicillin antibiotic causes MRSA formation with its adhesive properties. The occurrence of bacterial resistance is a complication of all the usual medical practices in recent times, so that the CA-MRSA (Community-Associated methicillin-resistant S. aureus) and HA-MRSA (Hospital-acquired methicillin-resistant S. aureus) appear (Cihaliva et al., 2015). The prevalence of MRSA in various hospitals in the world ranges from 2$70 \%$ with an average rate of $20 \%$ (Yuwono \& Biomed, 2010) and causes major risk and also potentially causes significant mortality and morbidity rates in human populations because of the ability to form a biofilm. Biofilm have an enormous impact on healthcare and are estimated to be associated with $65 \%$ of nosocomial infections (Kaur \& Wankhede, 2014).

Biofilm is structured communities of bacterial cells enclosed in a self-produced polymeric matrix and adherent to an inert or living surface (Phil, 2011). Infection followed by biofilm formation becomes a major problem, as it is difficult to be handled effectively by the host's immune system and resistant to treatment with antimicrobials (Cavaliere et al., 2014). Several infections caused by gram-positive bacteria, including those are caused by S.epidermidis, S. aureus and Enterococci are proved very difficult to treat with partial antibiotic therapy due to their very high natural resistance levels and partly because they form a biofilm (O'Toole et al., 2000). Biofilm formation of S.aureus is managed by PIA expression which mediates the adherents between cell to cell and it is a product from a gene of ica ABCD (Kaur \& Wankhede, 2014).

The test of biofilm formation by MtP method which was obtained from the result of all tested Staphylococcus $s p$. (MSSA1, MSSA2, and MRSA1 isolates), and it is included in the category of moderate biofilm producer. The microtiter plate (MtP) method is used for measuring and quantifying the ability of bacterial isolate adherent. Bacterial cells adhere to the substrate or well wall on a microtiter plate and form a multicellular community which is a core stage in the occurrence of infection and these characteristics become as one of the virulence factors in microorganisms, especially bacteria (Moghada et al., 2014). This research result is a little bit different from the result that was obtained by Moghadam, Pourmand, and Aminharati (2014) where their research shows that there was $62,5 \%$ of MRSA isolate that was able to form a moderate biofilm, while $40 \%$ of MSSA did not form biofilm. This observation shows that the biofilm formation on bacteria very depended on the condition of growth and indicated that the use of adding various sugars was essential for biofilm formation (Terki, 2013). Gowrishhanker et al. (2016) in his research shows that 
there were $44(69,8 \%)$ positive isolates of a total of 63 MRSA isolates that formed biofilm by biofilm formation test with MtP method.

In this research, ica operon expression and biofilm formation on Staphylococcus sp. bacteria show varied results. It is suspected that biofilm expression was affected by environment signal and could induce an external stress response. Biofilm expression could be also affected by the presence of iron, where its maximum expression occurs at low iron concentration (Terki, 2013). The product of ica A gene is a homologous transmembrane protein with $\mathrm{N}$-acetyl-glucosamin yltransferase which requires ica $\mathrm{D}$ gene product for its optimum activity. $\mathrm{N}$-acetyl-glucosamine oligomer that is produced by ica AD reaches a maximum length of 20 residues and it occurs only when ica AD is coexpressed with ica $\mathrm{C}$, which allegedly encodes a membrane protein whose oligomeric chain is longer (O'Gara, 2007).

Detection of ica A and D genes in this research shows that it is positive for both genes on MRSA1 isolate. This is in accordance with the results obtained from Moghadam, Pourmand and Aminharati (2014) which of the 40 MRSA isolates tested show that all those isolates are positive to ica A and ica D genes. Several studies have also shown the importance of the role of ica A and ica $\mathrm{D}$ genes in biofilm formation. Ica $\mathrm{A}$ and ica $\mathrm{D}$ genes are needed to form PIA, while PIA is needed to adhere and produce biofilm. MRSA isolates is a resistant isolate to some antibiotics which is too much to form biofilm structure, so that it could be suspected that most pathogens that MDR (Multi-Drug Resistant) often becomes biofilm producer (Moghadam et al., 2014). The cells that form biofilm have increased resistance to antibiotics compared to the resistance shown by planktonic cells that protection mechanism is considered

\section{Acknowledgment}

This work was supported by funding from Direktorat Jenderal Penguatan Riset dan Pengembangan, Kementrian Riset, Teknologi dan Pendidikan Tinggi on Penelitian Dosen Pemula Tahun 2017.

\section{References}

The first multicenter study of methicillin resistance Staphylococus aureus in Indonesian hospitals. 2008. The $13^{\text {th }}$ International Symposium on Staphylococci and Staphylococcal Infection.

Cavaliere, R., Ball, J.L., Turnbull, L. \& Whitchurch, C.B. 2014. The biofilm matrixdestabilizers, EDTA and Dnase I, enhance the susceptibility of nontypeable Hemophilus influenza biofilms to treatment with ampicillin and ciprofloxacin. Microbiology Open, 3(4), 557-567.

Cihalova, K., Chudobova, D., Michalek, P., Moulick, A., Guran, R., Kopel, P., Adam, V., \& Kizek, R. 2015. Staphylococcus aureus and MRSA Growth and Biofilm Formation after Treatment with Antibiotics and SeNPs. International Journal of Molecular Sciences, 16, 24656-24672.

Eftekhar, F. \& Dadaei, T. 2010. Biofilm formation and detection of ica $A B$ genes in clinical isolates of methicillin resistant Staphylococcus aureus. Iranian Journal of Basic Medical Sciences, 14(2), 132-136.

Ghafourian, S., Mohebi, R., Rezaei, M., Raftari, M., Sekawi, Z Kazemian, H., Mohseni, A., Karimi, S., \& Nourkhoda, S. 2013. as a barrier of absorbing and penetrating antibiotics through the biofilm matrix (Cavaliere et al., 2014).

On MSSA1 and MSSA2 isolates show ica A and ica D genes distribution which are different from MRSA, although both of them (MSSA 1 and MSSA 2) are known as forming moderate biofilm in biofilm test with MtP method. On MSSA 1 isolate, there is ica A gene, but there is no ica D gene. While on MSSA 2 isolate, there is no ica A gene, but there is ica $\mathrm{D}$ gene. In the research of Chokr et al., 2006 has also found this phenomenon, and it is suspected that this strain has variability in the sequence of locus ica gene which results in the production of polysaccharides reacting with serum anti-PIA. This is different from the results shown in MRSA isolates that are positive for the ica $\mathrm{A}$ and $\mathrm{D}$ genes. It is suspected that there is involvement of another ica gene other than ica A / $\mathrm{D}$ to biofilm formation, for example, ica B and ica C. PIA production is stimulated by action sensor proteins that are bound to membranes on bacterial cell walls. The PIA synthesis is catalyzed by a protein encoded by the ica operon, a gene group consisting of ADBC ica. The ica $\mathrm{C}$ gene may also be involved in the translocation of the extension of the polysaccharide on the cell surface. The ica B protein attached to the surface is then responsible for the deacetylation of the poly-N-acetylglucosamine molecule (O'Gara, 2007). Many of reports has demonstrated the significance of surface components in the biofilm formation of $S$. aureus such as the product of ica $A D B C$ operon, which encodes proteins for the synthesis of polysaccharide, poly-N-acetyl $\beta$-1-6glucosamine (PNAG). Also, few extracellular proteins, as well as cellboundadhesins (also called MSCRAMMs) are considered essential for the pathogenicity of $S$. aureus (Gowrishanker et al., 2016).

Comparative Analysis of Biofilm Development Among MRSA and MSSA Strains. Roumanian Archives of Microbiology and Immunology, 71(4), 175-82.

Gowrishankar, S., Kamaladevi, A., Balamurugan, K., \& Pandian, S.K. 2016. In Vitro and In Vivo Biofilm Characterization of Methicillin-Resistant Staphylococcus aureus from patients associated with pharyngitis infection. BioMed Research International, 2016, 1289157.

O'Gara, J.P. 2007. Minireview: Bioflm mechanisms and regulation in Staphylococcus epidermidis and Staphylococcus aureus. FEMS Microbiol Letters, 270(2007), 179-188.

Kaur, D.C., \& Wankhede, S. 2014. Biofilm formation and antimicrobial susceptibility pattern of methicillin resistant Staphylococcus aureus from wound infection. Asian Pacific Journal of Health Science, 1(4), 322-328.

Merritt, J.H., Kadouri, D.E., \& O’Toole, G.A. 2005. Growing and analyzing static biofilms. Current Protocols in Microbiology 1(1B.1), 1,17

Moghadam, S.O., Pourmand, M.R., \& Aminharati, F. 2014. Biofilm formation and antimicrobial resistance in methicillin-resistan Staphylococcus aureus isolated from burn patients, Iran. Journal of Infection in Developing Countries, 15;8(12), 1511-1517.

Nuryastuti, T. 2013. Evaluasi Pembentukan Bioflm, Distribusi Gen ica A/D serta Pola Kepekaan Antibiotik Isolat MRSA dan MSSA. Thesis. Universitas Gadjah Mada.

O’Toole, G., Heidi, B., Kaplan, H.B. \& Kolter, R. 2000. Biofilm formation as microbial as microbial development. Annual Review of Microbiology, 54, 49-79. 
Pihl, M. 2011. Microbial biofilms on peritoneal dialysis catheters Doctoral Dissertation in Odontology. Malmo University.

Riemann, H.P. \& Cliver, D.O. 2006. Foodborne infections and intoxications, Third Edition. Elsevier. USA.

Terki, K., Hassaine, H., Oufrid, S., Bellifa, S., Mhamedi, I., Lachachi, M. \& Timinouni, M. 2013. Detection of A and $D$ genes and biofilm formation in Staphylococcus spp. isolated from urinary catheters at the University Hospital of Tlemcen (Algeria) African Journal of Microbiology Research, 7(47), 5350-5357-
5357.

Yousefi, M., Pourmand, M.R., Fallah, F., Hashemi, A., Mashhadi, R., \& Nazari-Alam, A. 2016. Characterization of Staphylococcus aureus biofilm formation in urinary tract infection. Iranian Journal of Public Health, 45(4), 485-493.

Yuwono \& Biomed, H. 2010. Pandemi resistensi antimikroba: belajar dari MRSA. $J K K, 42(1)$. 